\title{
What astronomy can bring to the hi-tech party
}

\author{
Janet E. Jones \\ Astraguard Ltd. \\ Tubs Hill House, London Rd., Sevenoaks, UK \\ email: Janet@astraguard.com
}

\begin{abstract}
This is about the relationship between technology and astronomy, and in particular about people in astronomy getting into the hi-tech world. These people might be graduate students looking for jobs, they might be fully fledged academics wanting to exploit their knowhow. Whichever it is, it is essential to understand the differences between these two worlds and especially to understand that the hi-tech world only wants you for what you can bring to the table. So welcome to "the hi-tech party".
\end{abstract}

Keywords. Technology, astronomy, imaging

\section{The hi-tech party}

Astronomy is unique among the sciences in that experimentation is all but impossible - you can't poke a star or capture a galaxy. So our knowledge of the cosmos is based on data gathering and analysis, and computer modelling and display. This defines the nature of the skills of the astronomer. Surely these skills are of interest to prospective employers outside of academia?

It is frequently said that astronomy is unique in providing a wide range of skills, with an ability to acquire and handle data. For many astronomers there is also the knowledge of how to understand data using advanced statistical techniques and building sophisticated and well motivated models. Sounds good, but is that really useful in nailing down a career outside of astronomy?

Consider the following questions which look at the same problem from differing points of view:

If you were a student, would you seek a degree in astronomy as a useful qualification for a future career?

- If you were a technology employer, would you hire an astronomy graduate?

- If you were a budding entrepreneur, would you start a business based on astronomy-derived technology?

- If you were an investor, would you put your money into a venture based on astronomy-derived technology?

Each of these questions is important from the point of view of the person asking the question: each question seeks to assess a risk before a course of action is undertaken. So let us address each of these questions in turn.

\section{Joining the job market}

If you were a student, would you seek a degree in astronomy as a useful qualification for a future career? Two factors you might consider are 
- $\quad 80 \%$ of astronomers have left astronomy after 3 years.

- $\quad 55 \%$ of physics graduates in the UK take jobs in the financial sector.

So if you are in astronomy to become an astronomer, the long term odds don't look that good. The second remark tells you where these people go, or where they used to go before we were all struck down by the financial crisis. The reason for going into the financial sector is usually financial: having been a poor student you would like some reward for that sacrifice. Only idealists would say they don't care about money and financial stability.

It has been said that science and technology have been drained of talent by the financial sector because of the vastly superior rewards on offer. The potential rewards are certainly tempting.

\subsection{The Applicant's Perspective}

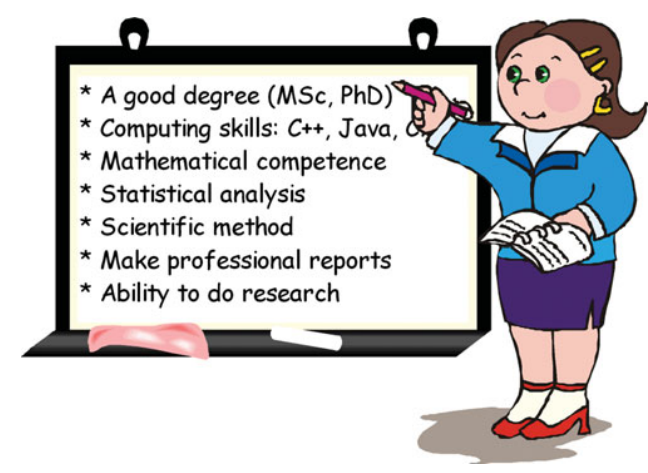

Figure 1. Being an applicant

Suppose you do want to leave academia and go into another area using your scientific talents. What do you need? Of course you will need your degree, that goes without saying, and a Ph.D. is certainly considered an advantage. If you have a $\mathrm{Ph} . \mathrm{D}$. in astronomy you will have a scientific approach to problem solving and a proven ability to execute a research project. You probably have a good level of mathematical competence, though you may not have a high enough level of mathematics for some areas in the financial sector, and you may not have sufficient knowledge of advanced statistical analysis.

There are two potential danger areas: you may only "speak Fortran", which is of relatively little use outside of specialist areas, and you may hate writing reports and doing documentation, which is essential for the commercial world. At least in the commercial world it is unlikely that you will ever use $\mathrm{LT}_{\mathrm{E} X}$, you will almost certainly have to use Microsoft Office.

The issue of programming languages is a vexed one. Employers in fact give candidates tests: skill tests and not infrequently psychological tests.

It is highly unlikely that anyone could just "pick up" $\mathrm{C}++$ and pass such tests in the face of competition with engineering students who have had three years of that.

\subsection{The Employer's Perspective}

If you were a technology employer, would you hire an astronomy graduate? To answer this question let us look at a more general question: as an employer, what qualifications are of greatest importance when seeking technical staff?

Some of the answer is shown in figure 2 . From the point of view of the person just finishing a Ph.D. this list looks fine, though

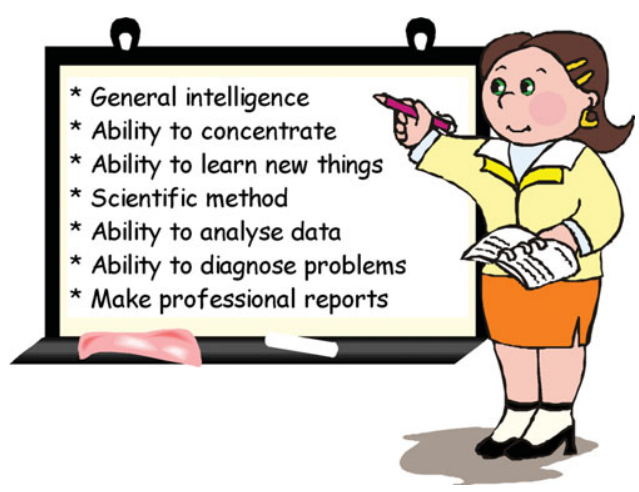

Figure 2. The employer point of view in practice the last two are potential stumbling blocks. Employers, particularly large 
corporations, will often use recruitment agencies who will give potential candidates for jobs psychological tests and aptitude tests.

Very large corporations may still go through recruitment agencies, but may prefer to use their own Human Resources departments to do the testing. Getting a job is a serious business!

\section{The entrepreneurial game}

So you are considering starting up your own company exploiting an idea based around your special know-how? Look at it from the scientist's point of view: what ingredients are needed for a successful start-up?

Twenty five years ago, I and my husband Bernard set out on a journey to found a small business utilising technology derived from our astrophysical knowledge. The following presents a personal point of view of the problems that we encountered, and an assessment of how I think the technology transfer process can be improved.

\subsection{What was easy}

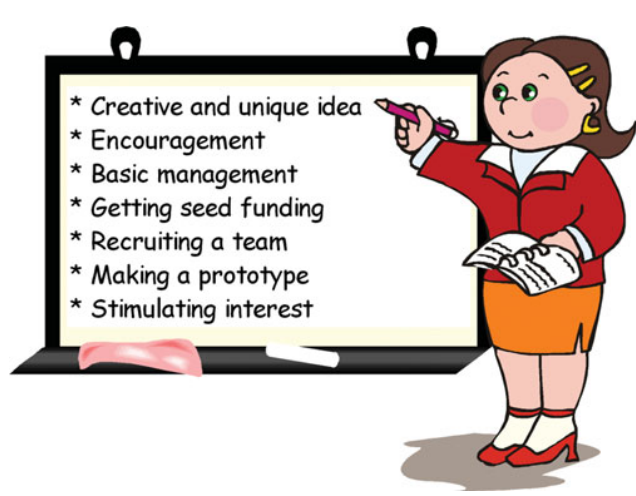

Figure 3. Being an entrepreneur

Some of the necessary ingredients in getting started are shown in figure 3. Perhaps the central issue is the unique idea - if it is not unique nobody is going to consider throwing money at it. But whoever does fund it is going to want to see capable management. Taking an MBA might not be a bad idea, but the key requirements are the ability to plan, and some level of competence at financial management.

The realisation of the idea will first see the light of day as a prototype which will serve many purposes, not the least of which is to show that the idea can be realised and to help explain precisely what the idea is.

To develop the prototype you will need a team: a team of two is better than a team of one, and it may be necessary to involve others with diverse skills that you do not possess. The team is a pretty essential ingredient unless you can do absolutely everything yourself.

\subsection{What were the traps?}

Going off and "doing technology" is considerably different than applying for telescope time or writing a paper! Many of the issues arise from the fact that when "doing technology" it is necessary to work with or alongside people with a different sense of ethics than academics are accustomed to.

Some of the issues are listed in figure 4 . The bottom line is that being an academic does not in any way prepare you for this kind of thing. Because you know you do not know everything (you admit this because you are an academic!) you are prepared to listen to

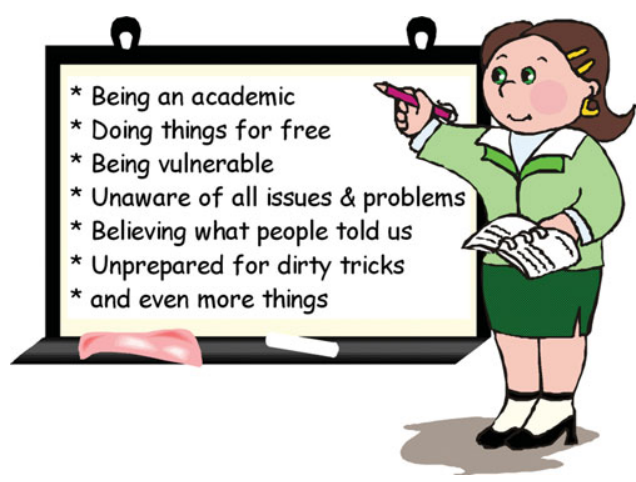

Figure 4. Traps for the unwary 
advice. But of course there is no refereeing standard in the world of giving advice - even if you pay for it. The cultural differences between the academic and business worlds is vast.

Dirty tricks? Yes, most of what you ever heard about avaricious business people is largely true. Their goals and interests do not necessarily coincide with the academic idea of doing technology.

\subsection{What was missing?}

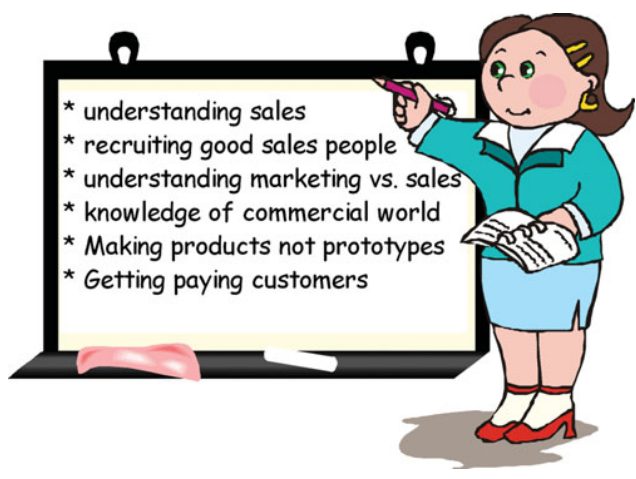

Figure 5. The missing ingredients

So what are some of the things that the academic education does not provide? Figure 5 lists some of these items, and the first thing to notice is that none of this has much to do with the technology itself! None of this stuff is taught in physics courses, why should it be? It is true that some universities do offer this kind of thing as an option, but of course the element of experience is not there.

The only place for gaining real experience is the real world, and so this is the classical situation where you cannot know about it until you have done it.

What would have helped? The bottom line of the commercial world is creating products with unique selling points and selling. No sales, no money and no future! However, getting to that point is far from easy, in fact it is far more difficult than one might at first imagine.

\subsection{The Investor Perspective}

Again, let us generalise - there are always exceptions but this is how it goes. For most people, investment in their idea comes, if at all, rather late in the game. Early investment for "proof of concept" may come from bank loans (you need to offer security for that like your house).

It is rare to interest investors simply on the basis of an idea that does not have some level of proof. Once you have proof of concept and a potential customer base, you may be able to raise "seed capital", though it may involve your selling a large percentage of your soul to a devil who will own it for eternity. Beyond that you can look for serious investment that will enable you to take your idea and the company to the dizzying heights of pubic flotation, where for little effort you will double, triple or quadruple your money overnight.

But you can rest assured that your investor will do even better than you do. That's what

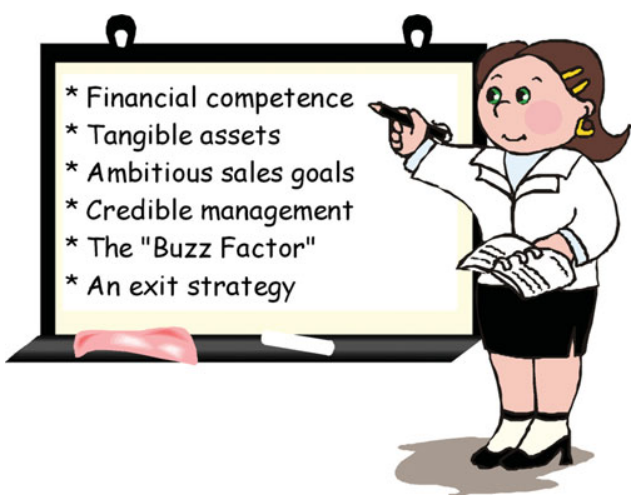

Figure 6. The investor point of view makes your idea interesting to an investor. So it is worth asking: What do investors look for in making an investment? That's relatively easy to answer, figure 6 gives some of the answers. The answers are perhaps surprising to the academic. None of this has much 


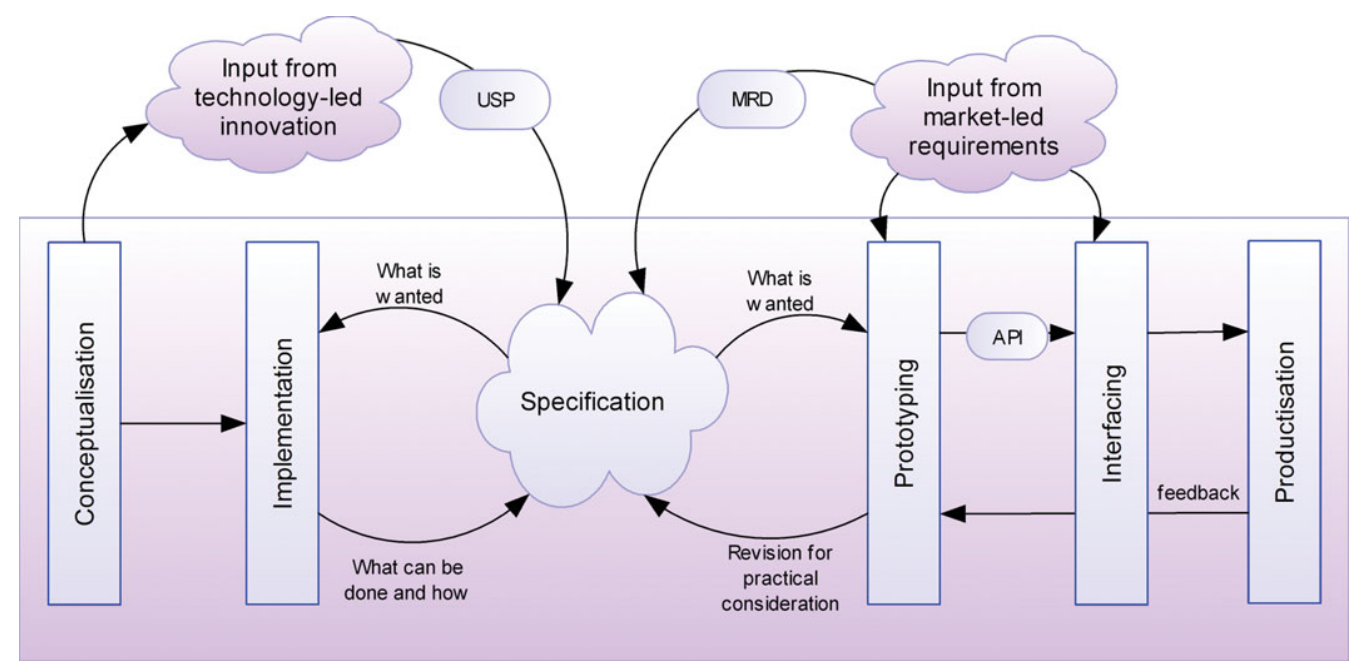

Figure 7. This diagram, describing our company's development process, reflects almost exactly the TRL measure used by some US government agencies to assess the maturity of evolving technologies. Acronyms: TRL $=$ Technology Readiness Level, USP $=$ Unique selling points, $\mathrm{MRD}=$ Market requirement document, API $=$ Application programming interface.

to do with the nature of what your wonderful invention actually does, nor of what you might be offering.

But the times are changing: what may come from the credit crunch?

\section{The technology transfer process}

Figure 7 shows the process of bringing pure science stimulated technology to market. The diagram has much in common with a NASA metric, the Technology Readiness Level $(T R L)$, that is used by US government institutions to quantitatively define the maturity of a technology. There is much debate about the value of TRL as a metric, but it nevertheless defines a process through which companies can map the flow of technology from pure science to commercial package. Here I have added the external inputs that are used to achieve the flow of development from concept, through implementation and prototypes to productisation.

This diagram is a map of the processes that must take place in order to have a successful hi-tech saleable products. One of the prime goals is to establish a functioning and profitable company and so this encapsulates how a working hi-tech company must function.

\subsection{Creating New Start-ups}

It is always good to point to successes, and there have been many of these. However, in the UK, only $2 \%$ of start-up companies are successful. Why is this? Furthermore, why do European attempts to replicate the US model fail to achieve the same level of success?

There have been many articles and papers published about this, mostly by economists, and people in business and government. The failure is blamed on weak links between business and universities, on funding methods in universities, on lack of incentives for European academics, on intellectual arrogance by European academics, etc. etc. Basically, they don't know, but there are many theories. However, all studies agree, the role of academics in commercialising their discoveries is critical. 
But why then is the US so effective in creating start-ups? My own answer is that the success is due to the fact that it has such a strong home market. Many alternative reasons have been given for the comparative success of the US, and there are elements of truth in most of these. From the point of view of a scientific entrepreneur, the strong home market is the most important factor.

\subsection{Merchant vs. Manufacturer}

Understanding whether you are a merchant or a manufacturer is also important. The distinction is important:

- A merchant business buys goods produced by others, and sells them on at a profit. The acquisition time is short, the choice of goods is very large, and the market is usually local.

- A manufacturing business makes goods, and sells them on to merchants to sell. The production time is long, the range of goods is very limited, and the market is wider, often global Technology transfer is a manufacturing process.

Coming to terms with the sales process required by each of these is very important. The strategies for the two are very different.

\subsection{What makes a company successful?}

Again we are into the realm of generalisation, but the elements listed in figure 8 seem to be pretty universal. It is the managing director of the company who sees to it that all this happens. The point of reference is the business plan which embodies all these details and on the basis of which the managing director reports to his/her board of directors.

The business plan is a very important document. It details how the company expects to make a profit and even goes so far as to make predictions against which performance can be measured. The important thing about business plan is that it is a living document:

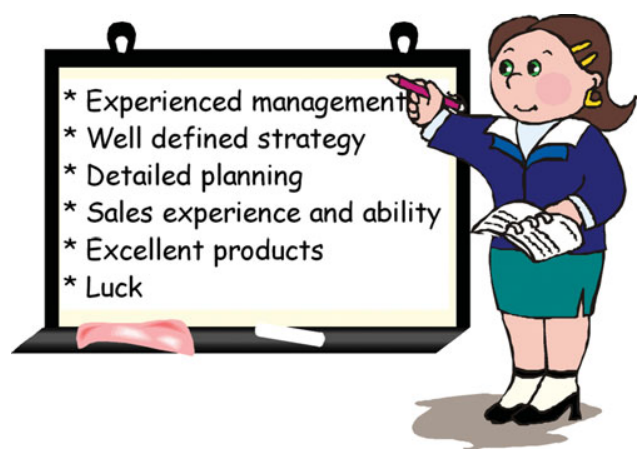

Figure 8. The elements of success its contents are not cast in stone and are generally expected to change with changing circumstances and changing markets.

\section{The bottom line}

It is a long haul from start to finish, if it ever does finish. The entire process, if it goes to completion, generally takes a long time. Of course there are great success stories of rags to riches in a short space of time, but these are relatively rare among the success stories. It should be remembered that only a small fraction of startups actually get anywhere.

\section{Acknowledgements}

I thank David Valls-Gabaud and the conference organisers for the opportunity to present this talk at the conference, and for their support. I thank Bernard Jones for help with the diagrams and with the $\mathrm{AT}_{\mathrm{E}} \mathrm{X}$ version of this article. 